\title{
A Controlled Trial of Educational Outreach to Improve Blood Transfusion Practice
}

\section{Citation}

Soumerai, Stephen B. 1993. "A Controlled Trial of Educational Outreach to Improve Blood Transfusion Practice." JAMA: The Journal of the American Medical Association 270 (8) (August 25): 961. doi:10.1001/jama.1993.03510080065033.

\section{Published Version}

doi:10.1001/jama.1993.03510080065033

\section{Permanent link}

http://nrs.harvard.edu/urn-3:HUL.InstRepos:32696160

\section{Terms of Use}

This article was downloaded from Harvard University's DASH repository, and is made available under the terms and conditions applicable to Other Posted Material, as set forth at http:// nrs.harvard.edu/urn-3:HUL.InstRepos:dash.current.terms-of-use\#LAA

\section{Share Your Story}

The Harvard community has made this article openly available.

Please share how this access benefits you. Submit a story.

\section{Accessibility}




\section{A Controlled Trial of Educational Outreach to Improve Blood Transfusion Practice}

Stephen B. Soumerai, ScD; Susanne Salem-Schatz, ScD; Jerry Avorn, MD; Christina S. Casteris, MS;

Dennis Ross-Degnan, ScD; Mark A. Popovsky, MD

Objective.-To determine whether brief, face-to-face educational outreach visits can improve the appropriateness of blood product utilization.

Design.-Randomized, controlled multicenter trial with 6-month follow-up.

Setting.-Surgical and medical services of two pairs of matched community and teaching hospitals in Massachusetts.

Participants.-One hundred one transfusing staff surgeons and attending medical physicians.

Intervention.-A professionally based transfusion specialist presented one surgical- or medical-service-wide lecture emphasizing appropriate indications, risks, and benefits of red blood cell transfusions; brief, graphic, printed educational guidelines; and one 30-minute visit with each transfusing physician. No data feedback was provided. Educational messages emphasized the lack of utility of the traditional threshold for red blood cell transfusions (hematocrit, 30\%) and transfusion risks (eg, viral hepatitis).

Measures.-Proportion of red blood cell transfusions classified as compliant or noncompliant with blood transfusion guidelines, or indeterminate 6 months before and 6 months after an experimental educational intervention.

Results.-Based on analyses of 1449 medical record audits of red blood cell transfusions that occurred 6 months before and 6 months after the educational intervention, the average proportion of transfusions not in compliance with criteria declined from 0.40 to 0.24 among study surgeons $(-40 \%)$ compared with an increase from 0.40 to $0.44(+9 \%)$ among control surgeons $(P=.006)$. These effects were consistent across procedure type and specialty. On average, study surgeons in the postintervention period performed transfusions when hematocrits were 2.0 percentage points lower than before the intervention $(28.3 \%$ preintervention vs $26.3 \%$ postintervention), and lower than in the control group (28.3\% preintervention and postintervention; $P=.04$ ). Likely savings in blood use for surgical services probably exceeded program costs, even without considering reduced risks of infection. No effects were observed among transfusions occurring in medical services, possibly because of substantially lower transfusion rates and lower pretransfusion hematocrits.

Conclusions.-Brief, focused educational outreach visits by transfusion specialists can substantially improve the appropriateness and cost-effectiveness of blood product use in surgery. More data are needed regarding the durability of changes in practice patterns and the health and economic benefits of such interventions.

(JAMA. 1993;270:961-966)

INCREASINGLY, scientific and policy debates on the continuing upward spiral of medical care costs and evidence of re-

\footnotetext{
From the Department of Social Medicine, Harvard Medical School, Boston, Mass (Drs Soumerai, Salem Schatz, and Ross-Degnan, and Ms Casteris); the Program for the Analysis of Clinical Strategies and the Department of Medicine, Harvard Medical School, Boston, Mass (Dr Avorn); and the American Red Cross Blood Services, Northeast Region, Dedham, Mass, and the Department of Medicine, Beth Israel Hospital, Harvard Medical School, Boston, Mass (Dr Popovsky).

Presented in abstract form at the annual meeting of the Association for Health Services Research, Chicago III, June 9, 1992.

Reprint requests to Harvard Medical School, 643 Huntington Ave, 2nd Floor, Boston, MA 02115 (Dr Soumerai).
}

experiments in the United States and Canada have demonstrated that targeted, professionally based, face-to-face educational outreach efforts did reduce unnecessary repeat cesarean sections and use of contraindicated or expensive drugs. ${ }^{2,5-7}$ In this study, we conducted a controlled multicenter trial of face-to-face educational outreach to communicate concise transfusion guidelines intended to improve the appropriateness of red blood cell $(\mathrm{RBC})$ utilization.

Blood transfusion practice is an important target for guideline implementation efforts. Over 11 million units of RBCs are transfused each year in the United States, ${ }^{8}$ costing roughly $\$ 2$ billion exclusive of the costs of volunteer effort and transfusionrelated infections. The decision to perform a transfusion on a patient carries measurable clinical risks and benefits. When blood is given for appropriate indications, it can prevent serious illness or death. However, nonindicated use of blood products can needlessly expose a patient to such risks as the human immunodeficiency virus, viral hepatitis, increased risk of perioperative bacterial infection, ${ }^{9}$ fluid overload, and hemolytic transfusion reactions, in addition to the economic costs associated with hospital personnel involved in processing and transfusing blood and treating adverse effects. Approximately $10 \%$ of transfusion recipients develop a troublesome or serious complication resulting from a transfusion. ${ }^{10,11} \mathrm{Al}$ though transfusion-associated hepatitis is often subclinical, about $50 \%$ of infected patients develop chronic hepatitis, and approximately $10 \%$ of these progress to cirrhosis. ${ }^{12}$

The exact extent of inappropriate use of blood products is not known, but published estimates for RBCs have been as high as $25 \% .^{13-16}$ While transfusion practices may have changed because of an increased awareness of the potential for HIV transmission, ${ }^{8}$ studies conducted since the onset of the acquired immunodeficiency syndrome (AIDS) epidemic are consistent with earlier work documenting inappropriate use of blood products. ${ }^{17,18}$ Recent reports and clinical guidelines on perioperative RBC transfusion published by the National Institutes of Health and the American College of Physicians concluded that inappropriate blood 
transfusions continue despite widespread concern about overuse of this scarce resource and the potential for transfusioninduced disease. ${ }^{13,19}$

A survey of 122 surgeons and anesthesiologists in three nonstudy hospitals identified gaps in knowledge and nonclinical factors that affect transfusion decision making. ${ }^{20}$ For example, $48 \%$ of physicians substantially overestimated the probability of inducing a myocardial infarction by withholding blood and allowing the hematocrit to fall below $30 \%$ in the absence of active heart disease and other indications for transfusion. Fortyone percent of surgeons agreed with the misbelief that "a low hematocrit can itself result in impaired postoperative wound healing." In addition, a subgroup analysis suggested that poorer transfusion knowledge was associated with higher rates of inappropriate transfusions. ${ }^{21}$

The above findings were used to design the educational materials and content of a brief, targeted, face-to-face educational outreach program offered by a transfusion-medicine expert in four Massachusetts hospitals. We hypothesized that a brief educational visit, conducted one-on-one with physicians who perform transfusions, to discuss gaps in knowledge identified in the previous survey, would significantly increase the appropriateness of blood product use compared with physicians not exposed to the program.

\section{METHODS}

We used a randomized controlled experimental design to measure changes in individual physician compliance with blood transfusion guidelines following the experimental education program. The surgical and medical services in two pairs of matched community and teaching hospitals in eastern Massachusetts were randomly assigned to study or control groups. To measure changes in physician practices, all transfusions were analyzed ( $n=2819$ transfusion episodes) for all target procedures or diagnoses for controlgroup and study-group physicians for 6 months before (through December 1988) and 6 months following the experimental intervention (through April 1990).

\section{Selection and Randomization}

Pairs of teaching and community hospitals were randomly selected from all hospitals within three health service areas in eastern and central Massachusetts. First, all hospitals were identified that had used at least $3000 \mathrm{U}$ of RBCs and performed over 50 hip repairs (one of the "target" procedures, International Classification of Diseases, Ninth Revision [ICD-9] codes 79.35 through 79.36$)^{22}$ in
1986 in order to ensure sufficient sample size for analysis. A minimum of $25 \mathrm{RBC}$ transfusions per 100 admissions overall was required to ensure sufficient volume of blood use. After one teaching hospital and one community hospital had been randomly selected from the entire list, a second hospital of each type was randomly identified from one of the other two health service areas to minimize the risk of experimental contamination due to physicians' practicing at multiple sites within a health service area. All four of the hospitals identified in the first selection agreed to participate in the study. One surgical service in each matched pair was then randomly assigned to the study group and the other to the control group; within each hospital the medical service was assigned to the treatment group opposite from surgery.

\section{Patient and Physician Samples}

Target surgical procedures were selected based on the frequency of procedures, frequency of blood use for the procedures, suspected inappropriate blood use (based on the literature and a pilot study conducted in four nonstudy hospitals), and reasonable medical consensus on appropriate or inappropriate transfusion practice for such cases. Procedures selected for the surgical sample included esophageal surgery and gastrectomy ( $I C D-9$ codes 42.00 through 46.99); cholecystectomy (ICD-9 codes 51.2 through 51.99); large-vessel surgery (ICD-9 codes 38.00 through 39.59 [except 39.27]); repair of hip fracture (ICD-9 codes 79.35 through 79.36), hip and knee replacements (ICD-9 codes 81.40 through 81.69); and discectomy (ICD-9 codes 80.50 and 81.00 through 81.09 ). Because of small numbers of patients receiving a transfusion in the medicine service, we defined the sample broadly as any admission that did not include a surgical procedure. This led to a much more heterogeneous group of patients in the medical sample than in the surgical sample.

All staff surgeons in orthopedic, vascular, and general surgery, and attending physicians in the department of medicine were included in the study if they ordered four or more RBC transfusions for target procedures or diagnoses in the 6-month preintervention period.

We identified for audit the medical records of all patients who received transfusions who underwent one of the targeted procedures or who met criteria for the medical sample, and who were attended by one of the study physicians or surgeons. Patients who received over $40 \mathrm{U}$ of blood were excluded, as were those who received transfusions with autologous or intraoperatively salvaged blood. Transfusions were attributed to the attending physician in both the community and teaching hospitals, even if the order for blood was generated by a resident in the latter. A previous physician surve ${ }^{20}$ indicated that attending physicians were perceived to be the key decision makers in transfusion decisions, even when they did not actually write the order. If a patient who was admitted for medical reasons subsequently underwent a surgical procedure, all transfusions during the episode of care were attributed to the operating surgeon.

\section{Explicit Criteria}

An audit instrument was designed to measure changes in compliance with a set of explicit criteria, based on the literature, published guidelines of the American College of Physicians and expert consensus panels, ${ }^{13}$ and the input of a local panel of surgeons, internists, and experts in transfusion medicine. Briefly, the audit criteria suggested that a transfusion would be indicated in the presence of a pretransfusion hematocrit of $24 \%$ or less, a fall in hematocrit of 6 percentage points or more within 24 hours, or a pretransfusion hematocrit between $24 \%$ and $30 \%$ in the presence of one of the following: angina within 24 hours prior to transfusion, myocardial infarction within 6 weeks prior to transfusion, an electrocardiogram indicating acute ischemia or acute infarct, or blood loss of $1000 \mathrm{~mL}$ or greater prior to transfusion. Patients with a pretransfusion hematocrit between $24 \%$ and $30 \%$ with none of these conditions, but who were either 75 years of age or older or had a history of coronary artery disease were placed in an "indeterminate" group because of a high degree of disagreement within the medical community about the indications for transfusion in these patients.

The unit of audit was the "transfusion episode," defined as all units of RBCs administered contiguously within a 12hour period. All transfusion episodes were scored against the explicit criteria and classified as compliant, noncompliant, or indeterminate. These categorizations were not intended as an absolute standard for appropriate practice in any given instance; rather, the audit was used to measure changes in the performance of groups of physicians over time, based on rates of compliance with explicit criteria derived from clinical guidelines. Likewise, the audit was not intended to identify or provide feedback for individual instances of "inappropriate" practices. The criteria were formulated with the understanding that under certain clinical circumstances, noncompliance with guidelines may be completely justified. 


\section{The Audit Process}

Information regarding characteristies of the patient and of each transfusion episode was abstracted from the hospital record by two trained medical record ab-

- stractors, using a computerized data collection program. Data elements included

- patient-level descriptive information (eg, age, sex, medical record number, and attending physician); clinical and operative information (eg, history of prior myocardial infarction, blood loss during procedure, and diagnosis and procedure $I C D-9$ codes); laboratory data (eg, hemoglobin level and hematocrit for the date of admission, the date of any procedure, and

- the dates of and 24 hours before all transfusions); and information on each RBC unit transfused (eg, date, time, and place). Data were entered by auditors directly into a laptop computer, and later were run through a computer-based algorithm to assess each transfusion episode for compliance with practice guidelines. The use of branching logic and internal consistency validation in the capture programs (eg, transfusion dates within admission and discharge dates, hematocrit approximately equal to three times the hemoglobin level) helped to ensure that all relevant information was collected for each case in a standard fashion, and that the information was coherent and logical. Reliability was assessed by comparing the responses of two auditors on 1145 items for 13 transfusion episodes; there was a $92 \%$ rate of agreement by auditors on all items abstracted from each record.

\section{- Educational Program Content}

To maximize program credibility and physician acceptance of educational messages, the intervention was created and described as an innovative educational program produced jointly by the Harvard Medical School and the American

- Red Cross Blood Services, Northeast Region. The experimental intervention consisted of printed materials presenting the transfusion guidelines in a concise and graphic manner, with appropriate references to the clinical literature; one group educational presentation on each service; and a single scheduled, 20 -minute to 30 minute face-to-face educational visit with each study physician, conducted by a transfusion medicine specialist based at the American Red Cross Blood Services, Northeast Region, Dedham, Mass, and Harvard Medical School, Boston, Mass (M.A.P.)

The program emphasized specific educational messages based in part on important knowledge deficits and other factors affecting blood transfusion decisions identified in our previous survey of 122 surgeons in another state ${ }^{20}$ and a pilot study of transfusion practices. The most important educational messages, derived in part from a National Institutes of Health consensus conference and from the transfusion literature, ${ }^{13}$ emphasized the inappropriateness of an automatic transfusion "trigger" hematocrit of $30 \%$. To illustrate that the cardiac risks of mild to moderate anemia should not be overemphasized, data were provided to indicate that in hemodynamically stable patients, cardiac output does not begin to increase until the hematocrit drops to about $27 \%$ or less. ${ }^{23}$ As in the 1992 American College of Physicians' guidelines on RBC use, ${ }^{19}$ the program recommended that threshold levels of transfusion in self-limited anemia can be reduced to hematocrit of $27 \%$ or less in many patients.

The program also reviewed the major indications for and contraindications to RBC transfusions, and emphasized that age or past cardiac history are not in themselves indications for blood use, and that transfusions do not improve wound healing. The guidelines also reviewed the most important risks and complications of RBC transfusions. Finally, the materials recommended maintenance of adequate intravascular volume as a more appropriate alternative to $\mathrm{RBC}$ transfusions used primarily to maintain blood pressure, and reevaluation of the continued need for blood after each unit and transfusion episode.

\section{Implementation of Intervention}

Approximately five half-day sessions were spent with the physician educator (M.A.P.) orienting him to the principles and techniques of interactive communication and persuasion used in previous studies through discussion and role playing. ${ }^{24}$ These principles included (1) clearly establishing the credibility of the source of the information and the messenger; (2) presenting both sides of controversies; (3) stimulating physician interaction to increase participation and define motivations for practice; (4) using graphs, illustrations, and headlines in printed educational materials to convey important messages during educational visits; and (5) repeating and reinforcing the most important behavior-change messages.

The hospital-based service rounds were conducted by the physician educator and consisted of 60-minute sessions, of which approximately 15 minutes were allotted for questions. To avoid contamination of control services, rounds were conducted exclusively for each experimental service. The one-on-one sessions were held at the office of the transfusing physician. Appointments were scheduled in advance by the physician counselor, who informed the physician that the purpose of the visit was educational and that the dura- tion would not exceed 30 minutes. Occasionally, surgeons mentioned specific anesthesiologists as important influences on transfusion practice; in these few cases, the anesthesiologists were visited as well. During all one-on-one visits, the discussion was confined to transfusion principles; individual data (performance) feedback was not provided.

\section{Statistical Analysis}

Because the physician was the primary unit of intervention, all transfusion data were aggregated and analyzed at this level. We observed changes between the preintervention and postintervention periods in the proportion of transfusion episodes in each physician's practice that did or did not meet the criteria. We also measured preintervention-to-postintervention changes in the physician-level average pretransfusion hematocrit (the mean of the last recorded hematocrit before each audited transfusion). We used general linear models to evaluate the statistical significance of the experimental condition on observed changes in study outcome variables from baseline to follow-up periods, controlling for type of study hospital (community vs teaching). These models were of the following form:

$$
\begin{gathered}
\text { Proportion }_{\text {post }}=\text { Proportion }_{\text {pre }}+\text { Experi- }^{\left(0 x p^{(0 / 1)}\right.} \\
\text { mental Group }
\end{gathered}
$$

The interaction between experimental group and hospital type was tested and found to be nonsignificant, demonstrating consistency in effects in both experimental hospitals; this term was therefore excluded from the models. All proportions were transformed prior to modeling using the arcsine transformation to normalize distributions and control for boundary effects ${ }^{25}$; all results were converted back to proportional form for presentation in the text and figures. Reported F-test values correspond to tests of the significance of the term for experimental group in these models using type III partial sums of squares.

To avoid selection bias, we used an intention-to-treat analysis in which physicians randomized to the intervention group who refused or were unable to schedule one-on-one visits were included in all analyses as members of that group. In addition, where appropriate, we plotted the observed physician-level changes (Proportion $_{\text {post }}-$ Proportion $_{\text {pre }}$ ) and 95\% confidence intervals by study group to describe the variation in physician responses to the intervention. Analyses were conducted separately for surgical and medical services. Excluding indeterminate cases from statistical analysis and considering only transfusions identified as either compliant or noncompliant with guidelines substantially increased the 
magnitude of observed effects; these indeterminate cases are conservatively included in all reported analyses.

\section{RESULTS}

Table 1 presents background characteristics of the four study hospitals and physicians who met entry criteria for target procedures, diagnoses, and transfusion rates. Study and control sites were comparable with respect to bed size and number of admissions. The distribution of medical and surgical specialties in the study and control hospitals was similar (Table 1). Orthopedic surgery was the dominant specialty in the physician samples of all four hospitals (44\% to $56 \%$ ) because of the high frequency of orthopedic procedures in the sample and associated transfusion rates. Study physicians were very receptive to the educational visits; $80 \%$ agreed to meet with the transfusion-medicine specialist, and the mean time per visit ranged from 29 to 31 minutes across the four study hospitals.

\section{Program Effects on Compliance}

Figure 1 presents data on the overall effects of the experimental education program on rates of compliance with the explicit criteria for all study and control surgeons, and stratified by communityand teaching-hospital settings. These data are based on 1449 transfusion episodes. Rates of compliance and noncompliance are not reciprocal due to the third group of indeterminate transfusions. At baseline, the average proportion of transfusion episodes that were noncompliant with guidelines was comparable across study and control surgeons. After the intervention, the average proportion of noncompliant transfusions declined from 0.40 to 0.24 among study surgeons compared with an increase from 0.40 to 0.44 among control surgeons ( $\mathrm{F}, 8.32 ; d f, 1$; $P=.006$ ). Conversely, the average proportion of transfusions that were compliant rose from 0.22 to 0.43 in the study group, and from 0.29 to 0.32 among control surgeons $(\mathrm{F}, 5.12 ; P=.03)$. No difference was observed between study and control groups in the average preintervention-to-postintervention change in the proportion of transfusions that were classified as indeterminate.

Observed differences between study and control groups were similar for teaching- and community-hospital surgeons (Fig 1), suggesting that the experimental intervention was equally likely to alter practice patterns in both communityand teaching-hospital settings.

Because of the limited number of study hospitals and the possibility that differences in case-mix and specialty distributions could confound observed differ-

Table 1.-Baseline Characteristics of Study and Control Hospitals*

\begin{tabular}{|c|c|c|c|c|}
\hline & \multicolumn{2}{|c|}{$\begin{array}{l}\text { Teaching } \\
\text { Hospltals }\end{array}$} & \multicolumn{2}{|c|}{$\begin{array}{l}\text { Community } \\
\text { Hospltals }\end{array}$} \\
\hline & $\begin{array}{l}\text { Study } \\
\text { Group }\end{array}$ & $\begin{array}{l}\text { Control } \\
\text { Group }\end{array}$ & $\begin{array}{l}\text { Study } \\
\text { Group }\end{array}$ & $\begin{array}{c}\text { Control } \\
\text { Group }\end{array}$ \\
\hline \multicolumn{5}{|c|}{ Hospital Data } \\
\hline No. of beds & 315 & 385 & 280 & 337 \\
\hline No. of admissions/y & 14000 & 12771 & 12627 & 11727 \\
\hline No. of audited transfusions at baseline & 471 & 237 & 592 & 194 \\
\hline \multicolumn{5}{|c|}{ Physician Data ( $n=101)$} \\
\hline No. of physicians in medicine & 15 & 15 & 17 & 14 \\
\hline No. of physicians in surgery & 9 & 8 & 14 & 9 \\
\hline $\begin{array}{l}\text { Proportion of surgeons by specialty } \\
\text { Orthopedics }\end{array}$ & 0.56 & 0.50 & 0.50 & 0.44 \\
\hline General surgery & 0.44 & 0.50 & 0.36 & 0.44 \\
\hline Vascular surgery/urology & 0 & 0 & 0.14 & 0.11 \\
\hline
\end{tabular}

${ }^{*}$ Classification of study and control groups was based on assignment of surgical services; medical services in each hospital were assigned to the opposite category.

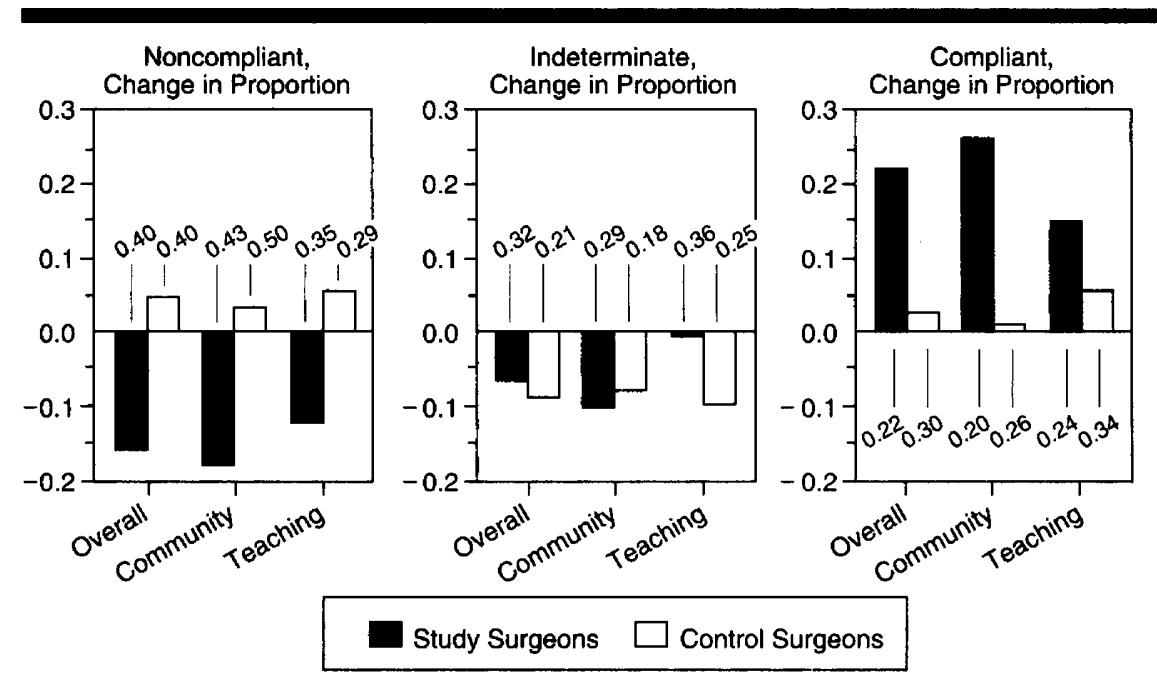

Fig 1.-Average changes (from preintervention to postintervention) in the proportion of red blood cell transfusions that were compliant, indeterminate, or noncompliant with explicit criteria by study group and by teaching-vs community-hospital settings. Averages were computed across the proportions of individual surgeons' caseloads of transfused patients ( $n=40$ surgeons, 1449 audited transfusions). Baseline proportions are presented for each bar.

ences in practice patterns, we conducted an additional analysis of differences between study and control physicians in the largest homogeneous subgroup of physicians, orthopedic surgeons $(50 \%$ of surgeons). This subgroup analysis confirmed the effects observed in the overall sample. The average proportion of transfusions that were noncompliant with guidelines declined from 0.30 before the intervention to 0.16 after the intervention among study orthopedic surgeons, compared with an increase from 0.29 to 0.43 among orthopedic surgeons in control services $(\mathrm{F}, 6.31 ; P=.02)$.

\section{Physician-Level Changes in Practice}

The means and distributions of practice-specific changes (from preintervention to postintervention) in the proportion of transfusions that were noncompliant or compliant with guidelines are presented by study group in Fig 2 . The data suggest that the observed changes in physician practices were not concentrated among a few "outliers." In fact, $74 \%$ of study physicians reduced the proportion of transfusions that were noncompliant, compared with only $35 \%$ of control surgeons. The same pattern of physician-level changes was observed for transfusions that were compliant.

\section{Changes in Hematocrit Thresholds}

We considered the possibility that the observed differences in compliance rates could reflect the quality of documentation of transfusion indications rather than differences in the quality of practice. Routinely collected laboratory data on pretransfusion hematocrit, the most important element in the explicit criteria, are not subject to this recording bias, and thus represent a more objective measure of the impact of the intervention. Since a principal educational message was that 


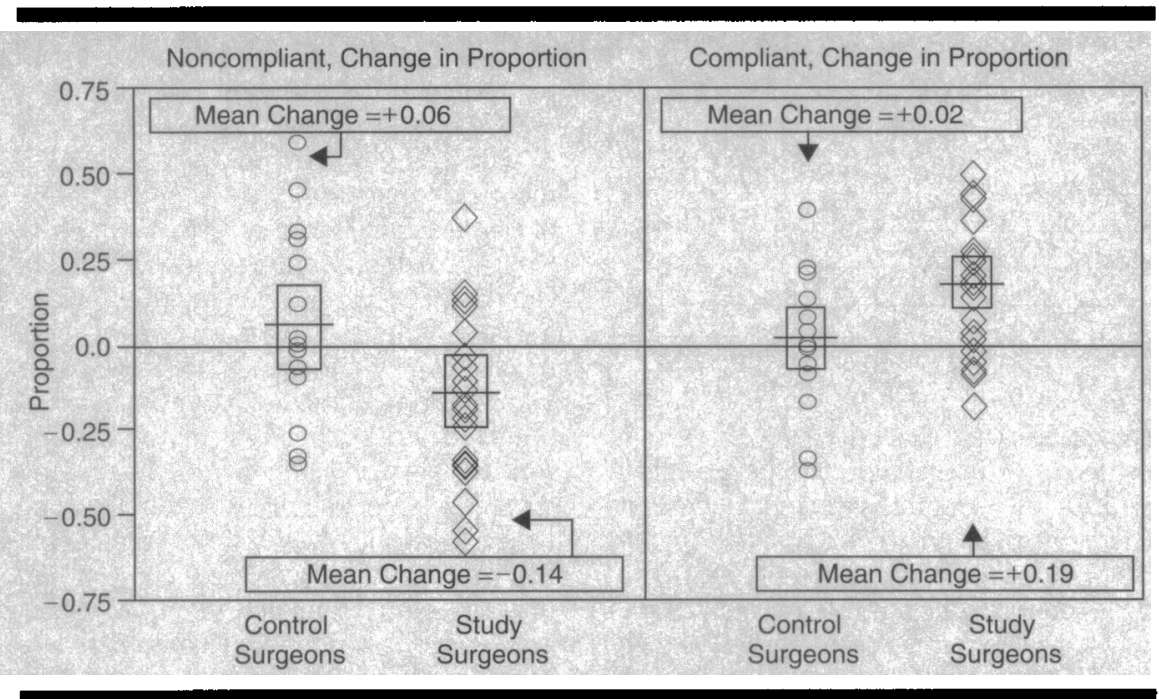

Fig 2.-Distributions of surgeon-specific changes in the proportion of transfusions that were noncompliant (left) or compliant (right) with criteria. Changes were calculated as physician-specific preintervention-topostintervention differences in the proportions of transfusions given for target cases ( $n=40$ surgeons, 1449 audited transfusions). A negative change indicates a reduction; a positive change, an increase. Boxes denote the $95 \%$ confidence limits around the mean change for each group (represented by the horizontal lines). Mean changes were based on raw physician-level data, and therefore differ slightly from means reported elsewhere in the text that are based on transformed data used in the general linear model analysis.

traditional hematocrit thresholds for transfusion (eg, $30 \%$ ), if used at all, should be lowered to hematocrit of $27 \%$ or less in uncomplicated hemodynamically stable patients, another measure of the success of the educational intervention is the change in pretransfusion hematocrit within study and control surgical practices. The data provide evidence that the intervention lowered the transfusion "trigger" substantially among study surgeons. At baseline, the average pretransfusion hematocrit (the mean of individual surgeons' average hematocrit for their total audited caseload) was virtually identical for study (28.3\%) and control (28.3\%) surgeons, and for community (28.3\%) and teaching $(28.2 \%)$ hospitals. After the intervention, the average pretransfusion hematocrit declined by 2.0 percentage points to $26.3 \%$ among study surgeons, while remaining at $28.3 \%$ among controls (average preintervention-to-postintervention change, -1.9 percentage points for study physicians and +0.01 percentage points for control physicians; Student's $t$ test, 2.11; $P=.04)$. This change was not due to an increase in the number of pretransfusion hematocrit determinations ordered; for example, among study surgical cases, this frequency dropped slightly from an average of 2.5 (preintervention) to 2.2 (postintervention), compared with 2.7 (preintervention) to 2.9 (postintervention) among controls. This result did not vary by specialty.

At baseline, $83 \%$ of study surgeons' transfused caseloads had average pretransfusion hematocrits over $27.0 \%$ (Table 2); in the postintervention period, only
$26 \%$ had average hematocrit levels greater than $27.0 \%$. The proportion of surgeons with average pretransfusion hematocrits of less than $24 \%$ remained low and constant over time (Table 2), suggesting that the intervention compressed the distribution of trigger hematocrits rather than shifting the entire curve, which might have increased risks of undertransfusion.

\section{Compliance on Medical Services}

Because of markedly lower rates of transfusions per target admission (unadjusted) in medicine (0.23) vs surgery (0.92) and the nonhomogeneous patient populations of the medical services, we were unable to obtain stable estimates of physician-level rates of compliance, and were thus unable to conduct statistical analyses of treatment effects in this group. Based on aggregate data, however, there was no perceptible change (from preintervention to postintervention) in rates of compliance with guidelines among study vs control physicians. Thirty percent (of 182 transfusions) ordered by study physicians on the medical services were noncompliant with guidelines at baseline; this proportion increased slightly to 0.32 after the intervention. Among control internists, the baseline proportion of transfusion episodes failing to comply with guidelines was 0.39 ; ervention. The average pretransfusion hematocrit on the medical services was already low before the intervention $(26.0 \%)$, and was not reduced after the program. this rate declined slightly to 0.32 postint-

\section{COMMENT}

The widespread inappropriate use of blood products has been noted frequently in the medical literature and has been the subject of National Institutes of Health consensus conferences and national practice guidelines. ${ }^{13,19}$ Yet the medical literature contains few adequately controlled studies of replicable, cost-effective, and nonregulatory strategies to improve blood transfusion decisions. Our data indicate that a brief and relatively inexpensive educational outreach program involving one personal visit by a transfusion specialist, concise guidelines, and one group seminar can increase adherence to guidelines on the use of RBCs in surgical patients. The intervention resulted in a clinically and statistically significant decrease in noncompliant transfusions in comparison with controls. More importantly, the program reduced the average pretransfusion hematocrit, the most objective measure of change in practice pattern, from $28.3 \%$ to $26.3 \%$ among study surgeons, with no change observed among controls. All effects were constant across teaching and community hospitals, and across surgical specialty. The lack of effect on the medical services may have been due in large part to low numbers of transfusions, much lower hematocrit in comparison with surgery, and a more heterogeneous patient population.

Although the consistency of intervention-control differences in physicianlevel changes in transfusion practice supports the internal validity of our findings, the limited number of hospitals included in the study may limit its generalizability. The above data suggest that surgical practice may represent a costeffective target for educational programs to improve blood transfusion practice. Further research is needed, however, to examine whether such effects are generalizable to other surgical settings and procedures. Similarly, the preexisting low medical transfusion rates (only about one quarter of the rate observed in surgery) and low pretransfusion hematocrits in medicine suggest that there may not be enough "room to move" to justify direct educational interventions on medical services of the type we evaluated. Further studies of larger medical samples are needed to determine whether the low transfusion rates in medicine are typical or whether educational programs should target different gaps in knowledge and practice than those identified in surveys of surgeons. ${ }^{20}$

Because we did not audit nontransfused cases, it is difficult to address the possibility of undertransfusion, which might have occurred as a result of the educational intervention. However, there 
Table 2.-Number and Percentage of Surgical Practices Within Each Range of Average Pretransfusion Hematocrits by Study Group and Time Period*

\begin{tabular}{lcccc}
\hline & \multicolumn{2}{c}{ Study Group } & \multicolumn{2}{c|}{ Control Group } \\
\cline { 2 - 5 } $\begin{array}{c}\text { Pverage } \\
\text { Hematocrit, } \%\end{array}$ & $\begin{array}{c}\text { Preintervention, } \\
\text { No. }(\%)\end{array}$ & $\begin{array}{c}\text { Postintervention, } \\
\text { No. (\%) }\end{array}$ & $\begin{array}{c}\text { Preintervention, } \\
\text { No. (\%) }\end{array}$ & $\begin{array}{c}\text { Postintervention, } \\
\text { No. (\%) }\end{array}$ \\
\hline 30 & $3(13)$ & 0 & $4(23)$ & $5(29)$ \\
\hline $27.1-29.9$ & $16(70)$ & $6(26)$ & $9(53)$ & $3(18)$ \\
\hline $24.1-27.0$ & $3(13)$ & $16(70)$ & $3(18)$ & $8(47)$ \\
\hline $0-24.0$ & $1(4)$ & $1(4)$ & $1(6)$ & $1(6)$ \\
\hline$* 40$ & & &
\end{tabular}

is little evidence to support the existence of such a problem. Furthermore, Table 2 suggests that surgeons generally did not wait (either before or after the intervention) until hematocrits were very low (under 24\%) before transfusing.

Another unanswered question is whether the changes observed in clinical decision making are durable beyond 6 months of follow-up. Because of the high cost of collecting patient-level chart and laboratory data for thousands of patients, few studies in the clinical decision-making literature have attempted follow-up periods beyond 6 months or 1 year. One exception is a study by Ray and colleagues ${ }^{26}$ which found that a similar physician "counselor" intervention was effective in reducing use of contraindicated antibiotics. Nevertheless, more work is needed to determine the duration of the effects of such interventions as well as the need for follow-up reinforcement visits to maintain such effects.

Future studies should also attempt to identify the most important mechanisms or processes of change. For example, what perceptions of risks among study physicians were most affected by the in-

\section{References}

1. Raskin IE, Maklan CW. Medical treatment effectiveness research: a view from inside the Agency for Health Care Policy and Research. Eval Health Professions. 1991;14:161-186.

2. Soumerai SB, McLaughlin TJ, Avorn J. Improving drug prescribing in primary care: a critical analysis of the experimental literature. Milbank Q. 1989; 67:268-317.

3. Soumerai SB, Avorn JL. Efficacy and cost-containment in hospital pharmacotherapy: state of the art and future directions. Milbank $Q .1984 ; 62: 447-474$. 4. Lomas J, Anderson GM, Domnick-Pierre K, Vayda E, Enkin MW, Hannah WJ. Do practice guidelines guide practice? the effect of a consensus statement on the practice of physicians. $N$ Engl $J \mathrm{Med}$. 1989;321:1306-1311.

5. Avorn JL, Soumerai SB. Improving drug therapy decisions through educational outreach: a randomized controlled trial of academically based 'detailing.' $N$ Engl J Med. 1983;308:1457-1463.

6. Soumerai SB, Avorn JL. Economic and policy analysis of university-based drug 'detailing.' Med Care. 1986;24:313-331.

7. Lomas J, Enkin M, Anderson GM, Hannag WJ Vayda E, Singer J. Opinion leaders vs audit and feedback to implement practice guidelines: delivery after previous cesarean section. JAMA. 1991;265: 2202-2207.

8. Surgenor DM, Wallace EL, Hao SH, Chapman RH. Collection and transfusion of blood in the United States, 1982-1988. N Engl J Med. 1990;322:1646-1651. tervention and accounted for the greatest change in behavior? Our preintervention surveys indicated that overconcern for risks of undertransfusion (eg, myocardial infarction) was responsible for a considerable number of transfusions when the hematocrit was only slightly below $30 \%$. However, most physicians overestimated the risks of transfusionrelated hepatitis and AIDS. While we believe that the careful targeting of the surgeons' concerns regarding undertranssuccess of the intervention, we also emphasized the major risks of overtransfusion as well; thus, it is not possible to determine which messages were most important in effecting change.

Although a formal cost-benefit analysis is beyond the scope of this report, preliminary data suggest that programs of direct education of active surgeons would produce net savings. In our study, surgeons transfused an average of 55.8 U per year for target cases at a cost of approximately $\$ 11160$ (at $\$ 200$ for acquiring, handling, testing, and administering each unit). ${ }^{27}$ Assuming conservatively that the intervention reduced over-

9. Triulzi DJ, Vanek K, Ryan DH, Blumberg N. A clinical and immunologic study of blood transfusion and postoperative bacterial infection in spinal surgery. Surgery. 1992;32:517-524.

10. Walker RH. Special report: transfusion risks. Am J Clin Pathol. 1987;88:374-378.

11. Dodd RY. The risk of transfusion-transmitted infection. $N$ Engl J Med. 1992;327:419-421.

12. Alter HJ. Chronic consequences of non-A, non-B hepatitis. In: Seeff LB, Lewis JH, eds. Current Perspectives in Hepatology. New York, NY: Plenum Publishing Corp; 1989:83-97.

13. Welch HG, Meehan KR, Goodnough T. Prudent strategies for elective red blood cell transfusion. Ann Intern Med. 1992;116:393-402.

14. Palermo G, Bove J, Katz AJ.Patterns of blood use in Connecticut. Transfusion. 1980;20:704-710.

15. Blumberg N, Laczom A, McMican A, Heal J, Arvan D. A critical survey of fresh-frozen plasma use. Transfusion. 1986;26:511-513.

16. Tartter PI, Barron DM. Unnecessary blood transfusion in elective colorectal cancer surgery. Transfusion. 1985;25:113-115.

17. Mozes B, Epstein M, Ben-Bassat I, Modan B, Halkin H. Evaluation of the appropriateness of blood and blood product transfusion using preset criteria. Transfusion. 1989;29:473-476.

18. Goodnough LT, Johnston MFM, Toy PT, the Transfusion Medicine Academic Award Group. The variability of transfusion practice in coronary bypass surgery. JAMA. 1991;265:86-90. fusion may have been a key factor in the all transfusion rates by only $10 \%$ for 1 year (after which effects were assumed to decay immediately to $0 \%$ ), and that transfusion-medicine specialists can visit three physicians per day, the estimated savings generated from each day of educational visits (approximately $\$ 3300$ ) are about four times greater than the daily direct cost (about $\$ 750$ for salary and benefits, travel, and educational materials). Assuming much lower savings would still yield substantial net economic benefits. These estimates are conservative, since they exclude likely savings in surgeons' practice outside the study hospital, lower rates of transfusion for nontargeted cases, reduced costs of infections and transfusion complications, and health benefits due to increased appropriateness of blood use.

Our findings suggest that blood-collection agencies and hospitals might collaborate in the adoption of such innovations. Not only do savings from reduced blood transfusion appear to exceed the costs of an operational program, but also more appropriate transfusions would lead to less risk to patients and provide better allocation of this scarce resource.

This study was supported by grant HSO5300 from the Agency for Health Care Policy and Research, US Department of Health and Human Services, Rockville, Md.

We are indebted to the four study hospitals and physicians without whose cooperation this work would have been impossible. We thank Sherry Hawley and Helen Glazer for abstracting the medical records; Johanna Pindyck, MD, Harold Kaplan, MD, Margo Kruskall, MD, Robert Reiss, MD, Robert Thurer, MD, and Carl Wolf, MD, for guidance and expertise on clinical issues and the transfusion audit; and Laura Goldberg, MA, for preparation of the manuscript.

19. American College of Physicians. Practice strategies for elective red blood cell transfusion. Ann Intern Med. 1992;116:403-406.

20. Salem-Schatz SR, Avorn J, Soumerai SB. Influence of clinical knowledge, organizational context and practice style on transfusion decision making. implications for practice change strategies. JAMA $1990 ; 264: 476-483$

21. Salem-Schatz SR, Avorn J, Soumerai SB. Influence of knowledge and attitudes on the quality of physicians' transfusion practice. Med Care. In press. 22. World Health Organization. Manual of the In ternational Statistical Classification of Diseases, Injuries, and Causes of Death, Based on the Recommendations of the Ninth Revision Conference, 1975. Geneva, Switzerland: World Health Organization; 1977.

23. Watkins GM, Rabelo A, Bevilacqua RG, et al Bodily changes in repeated hemorrhage. Surg Gynecol Obstet. 1974;139:161-175.

24. Soumerai SB, Avorn J. Principles of educationa outreach ('academic detailing') to improve clinical decision making. JAMA. 1990;263:549-556.

25. Snedecor GW, Cochran WG. Statistical Meth ods. 7th ed. Ames: Iowa State University Press; 1980 26. Ray WA, Schaffner W, Federspiel CF. Persistence of improvement in antibiotic prescribing in office practice. JAMA. 1985;253:1774-1776.

27. Forbes JM, Anderson MD, Anderson GF, Bleecker GC, Rossi EC, Moss GS. Blood transfusion costs a multicenter study. Transfusion. 1991;31:318-323. 